\title{
Mechanochemically synthesized mesoporous alumina: a smart new-generation sorbent for preparation of chromatographic ${ }^{188} \mathrm{~W} /{ }^{188}$ Re generator
}

\author{
Rubel Chakravarty ${ }^{1,3}$ (D) Jitendra Bahadur ${ }^{2} \cdot$ Sharad Lohar $^{1} \cdot$ Sachin Jadhav $^{1} \cdot$ Debasis Sen $^{2} \cdot$ Sudipta Chakraborty $^{1,3}$
}

Received: 23 June 2020 / Accepted: 22 December 2020 / Published online: 11 January 2021

(C) The Author(s) 2021 OPEN

\begin{abstract}
In an effort towards affordable availability of chromatographic ${ }^{188} \mathrm{~W} /{ }^{188}$ Re generators for widespread clinical use, we report the mechanochemical synthesis of mesoporous alumina as an advanced sorbent material for preparation of the generator. The synthesized material exhibits remarkably high sorption capacity $(550 \pm 12 \mathrm{mg} \mathrm{W} / \mathrm{g})$, which is adequate for preparation of clinical-scale generators using low specific activity (LSA) ${ }^{188} \mathrm{~W}$ produced in medium flux research reactors. Sorption of ${ }^{188} \mathrm{~W}$ in mesoporous alumina follows Freundlich adsorption isotherm and pseudo second order kinetics, indicating that the process is chemisorption. A clinical-scale $(\sim 14.0 \mathrm{GBq}){ }^{188} \mathrm{~W} /{ }^{188}$ Re generator was developed and its performance was evaluated over a period of 6 months. Rhenium- 188 could be consistently obtained from the generator with high yield $(>80 \%)$ and it met all the requirements for clinical use. The present strategy is expected to increase the scope of separation chemistry for availing clinical-grade ${ }^{188}$ Re for the benefit of millions of cancer patients world over.
\end{abstract}

Graphic abstract

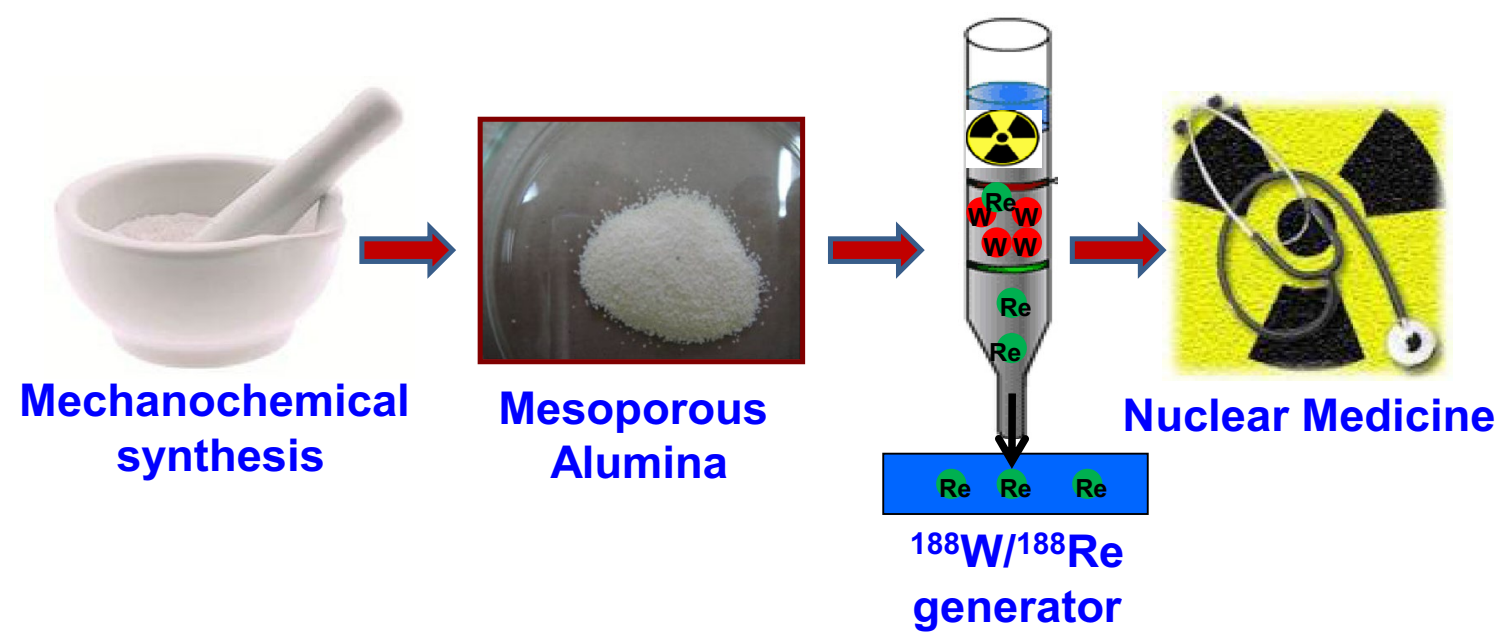

Supplementary Information The online version contains supplementary material available at https://doi.org/10.1007/s42452-020-04053 $-7$.

$\triangle$ Rubel Chakravarty, rubelc@barc.gov.in; rubelchakravarty@gmail.com | Radiopharmaceuticals Division, Bhabha Atomic Research Centre, Trombay, Mumbai 400085, India. ${ }^{2}$ Solid State Physics Division, Bhabha Atomic Research Centre, Trombay, Mumbai 400085, India. ${ }^{3}$ Homi Bhabha National Institute, Anushaktinagar, Mumbai 400094, India. 
Keywords ${ }^{188} \mathrm{~W} /{ }^{188}$ Re generator C Column chromatography · Mechanochemical synthesis · Mesoporous alumina . Nuclear medicine . Sorbent

\section{Introduction}

Radionuclide generators continue to play an imperative role in providing radioisotopes for use in nuclear medicine. Efficiency, reliability, safety and cost-effectiveness are the key parameters that govern the development of next-generation radionuclide generators for regular usage in clinical context. To a large extent, progress in design of improved radionuclide generators is dependent on the advancements in separation science and technology [1]. Owing to its simplicity and convenience to use in hospital radiopharmacies, the column chromatographic separation technique has found the widest application in development of radionuclide generators. Basically, the 'heart' of any column chromatographic separation process is the sorbent and hence progress in this field is related to evolution of materials chemistry towards synthesis of advanced sorbent materials.

Synthesis of advanced sorbent materials with high capacity and improved performance towards development of radionuclide generators has now become a continuing object of research with potential for clinical translation [2]. In this regard, sorbent materials with regular and relatively large mesopores tend to become indispensable. There have been numerous reports of synthesis of mesoporous materials over the last several years [3-7]. Driven by the need for new, cleaner, scalable, highly efficient and more sustainable synthetic methodologies, solid state mechanochemical approaches for synthesis of mesoporous materials has seen a reawakening during the past few years $[8,9]$. These techniques have not only been demonstrated as feasible alternatives to conventional solution-based syntheses, but they have also received consideration for their ability to enable high mesoporosity and thus develop novel sorbents for radionuclide generators. The solid-state synthesis route is easily amenable for scale up for synthesis of large quantities of sorbents required for the preparation of multiple radionuclide generators in order to meet the demands of the nuclear medicine community.

Rhenium-188 ( $\mathrm{T}_{1 / 2}=16.9 \mathrm{~h}, \mathrm{E}_{\max }=2.12 \mathrm{MeV}, 155 \mathrm{keV}$ $\gamma$-ray) is an established therapeutic radioisotope that can be obtained in a no-carrier-added (NCA) form via ${ }^{188} \mathrm{~W} /{ }^{188} \mathrm{Re}$ generator for preparation of a wide variety of radiopharmaceuticals [10]. The parent ${ }^{188} \mathrm{~W}$ can be produced with adequate specific activity by double neutron capture i.e. ${ }^{186} W(n, \gamma){ }^{187} W(n, \gamma){ }^{188} W$ reaction on enriched ${ }^{186} \mathrm{~W}$ target in high flux research reactors $\left(>10^{15} \mathrm{n} \cdot \mathrm{cm}^{-2} \cdot \mathrm{s}^{-1}\right)$ [10]. There are only very few operational high flux research reactors in the world. As a result, the widespread and cost-effective availability of clinically useful ${ }^{188} \mathrm{~W} /{ }^{188} \mathrm{Re}$ generators is compromised. In order to enhance the scope of utilization of ${ }^{188} \mathrm{Re}$ in clinical domain, it is essential to utilize relatively LSA ${ }^{188} \mathrm{~W}$ produced in medium flux research reactors for the preparation of ${ }^{188} \mathrm{~W} /{ }^{188}$ Re generators. According to the International Atomic Energy Agency-Research Reactor Database (IAEA-RRDB), there are more than 50 operational medium flux research reactors world over and they are located in good geographical distribution to meet the supply logistics [11]. Utilization of LSA ${ }^{188} \mathrm{~W}$ produced in these research reactors mandates the need for high capacity advanced sorbent materials for preparation of clinically useful ${ }^{188} \mathrm{~W} /{ }^{188}$ Re generators. In the past, many high capacity sorbent materials such as polymeric zirconium compound, polymeric titantium oxychloride, synthetic alumina, polymer embedded nanocrystalline titania, nanocrystalline zirconia and nanocrystalline alumina, etc., have been reported for preparation of chromatographic ${ }^{188} \mathrm{~W} /{ }^{188}$ Re generators [10, 12-19]. Despite their high sorption capacity, most of these generators used high specific activity ${ }^{188} \mathrm{~W}$ produced in high flux research reactors. In fact, the development of clinicalscale generators using LSA ${ }^{188} \mathrm{~W}$ produced in medium flux reactors is yet to commence in commercial settings.

In this study, we report the synthesis of mesoporous alumina sorbent by solid state mechanochemical approach and its utilization as a chromatographic sorbent in preparation of ${ }^{188} \mathrm{~W} /{ }^{188}$ Re generator using LSA ${ }^{188} \mathrm{~W}$ produced in a medium flux research reactor. The sorption characteristics of the material were investigated and conditions were optimized for chromatographic separation of ${ }^{188} \mathrm{Re}$ from ${ }^{188} \mathrm{~W}$. Detailed quality assessment tests were carried out over a period of 6 months to analyze the suitability of ${ }^{188} \mathrm{Re}$ obtained from the ${ }^{188} \mathrm{~W} /{ }^{188} \mathrm{Re}$ generator for clinical use. To the best of our knowledge, this is the first study on detailed investigation of tungsten-sorption characteristics of mesoporous alumina and its utilization as a chromatographic sorbent for preparation of a clinical-scale ${ }^{188} \mathrm{~W} /{ }^{188}$ Re generator using ${ }^{188} \mathrm{~W}$ produced in a medium flux research reactor. 


\section{Experimental}

Enriched (99.9\% in $\left.{ }^{186} \mathrm{~W}\right)$ tungsten oxide was purchased from Isoflex, Russia. All other chemicals were purchased from Sigma-Aldrich and used as received.

Mesoporous alumina was synthesized by mechanical grinding of aluminum isopropoxide and glucose taken in different molar ratios $(1: 1,1: 1.25,1: 1.5,1: 1.75$ and 1:2) in an agate mortar at room temperature for $1 \mathrm{~h}$. After grinding, the reaction mixture was calcined in a furnace at $500{ }^{\circ} \mathrm{C}$ for $2 \mathrm{~h}$. The lump obtained after calcination was crushed and sieved to get free flowing particles of 50-100 mesh size. The detailed procedure for optimization of the synthesis protocol and thorough characterization of the synthesized material are described in the Supporting Information.

For understanding the sorption of tungsten on mesoporous alumina synthesized under the optimized conditions, ${ }^{187} W$ produced via ${ }^{\text {nat }} W(n, \gamma){ }^{187} W$ reaction by irradiation of natural tungsten oxide powder in the Dhruva reactor at a flux of $1 \times 10^{14} \mathrm{n} \cdot \mathrm{cm}^{-2} \cdot \mathrm{s}^{-1}$ for $7 \mathrm{~d}$ was used as radiotracer. For this, neutron irradiated ${ }^{n a t} \mathrm{WO}_{3}$ powder was dissolved in $4 \mathrm{M} \mathrm{NaOH}$ solution in presence of few drops of $30 \% \mathrm{H}_{2} \mathrm{O}_{2}$ to convert it into $\left[{ }^{187} \mathrm{~W}_{\mathrm{N}} \mathrm{Na}_{2} \mathrm{WO}_{4}\right.$. The distribution coefficients $\left(\mathrm{K}_{\mathrm{d}}\right)$ values of tungstate and perrhenate ions for the sorbent matrix were measured at different $\mathrm{pH}$, using ${ }^{187} \mathrm{~W}$ and ${ }^{188} \mathrm{Re}$ as radiotracers, as per the procedure described in the Supporting Information. Sorption studies were carried out both by batch equilibration method as well as under dynamic (column flow) condition. In batch equilibration method, an accurately weighed amount of sorbent (50 $\mathrm{mg}$ ) was taken in a stoppered glass conical flask and equilibrated with $10 \mathrm{~mL}$ of the tungstate solution of varying concentration $(1,2.5,3.7,5.6,7.4 \mathrm{mg} \mathrm{W} / \mathrm{mL})$, spiked with $\sim 370 \mathrm{kBq}(10 \mu \mathrm{Ci})$ of ${ }^{187} \mathrm{~W}$ for $4 \mathrm{~h}$ at $\mathrm{pH}$ 3. Subsequently, the contents were filtered and the activity of the filtrate was compared with that of the standard solution taken from the equilibrium mixture before incubation with the sorbent. Similarly, kinetic studies were carried out by taking $3.7 \mathrm{mg} \mathrm{W} / \mathrm{mL}$ solution $(\mathrm{pH} \sim 3$ ) spiked with $\sim 370 \mathrm{kBq}(10 \mu \mathrm{Ci})$ of ${ }^{187} \mathrm{~W}$ and sorption capacities were determined at different time intervals as described above. The dynamic sorption capacity was determined by passing $10 \mathrm{mg} \mathrm{W} / \mathrm{mL}$ solution spiked with $\sim 370 \mathrm{kBq}$ $(10 \mu \mathrm{Ci})$ of ${ }^{187} \mathrm{~W}$ through a chromatographic column packed with $1 \mathrm{~g}$ of mesoporous alumina at a flow rate of $1 \mathrm{~mL} / \mathrm{min}$, as per the reported procedure [9].

The theoretical specific activity of ${ }^{188} \mathrm{~W}$ produced by double neutron capture reaction on ${ }^{186} \mathrm{~W}$ target at different flux conditions was calculated by simplified Bateman equations as detailed in the Supporting Information.
Under the optimized conditions, ${ }^{188} \mathrm{~W}$ was produced by irradiation of enriched $\left(99.9 \%\right.$ in $\left.{ }^{186} \mathrm{~W}\right)$ tungsten oxide $(1.25 \mathrm{~g})$ at a flux of $1.5 \times 10^{14} \mathrm{n} . \mathrm{cm}^{-2} \cdot \mathrm{s}^{-1}$ for 6 months. Post irradiation, the neutron irradiated ${ }^{186} \mathrm{WO}_{3}$ powder was converted to [ ${ }^{188} \mathrm{~W} \mathrm{Na}_{2} \mathrm{WO}_{4}$ by dissolving it in $20 \mathrm{~mL}$ of $4 \mathrm{M} \mathrm{NaOH}$ containing few drops of $30 \% \mathrm{H}_{2} \mathrm{O}_{2}$. The ${ }^{188} \mathrm{~W} /{ }^{188}$ Re generator was prepared by taking $4 \mathrm{~g}$ of mesoporous alumina in a chromatographic column placed in a lead shielded assembly. The activity was loaded in the column by passing ${ }^{188} \mathrm{~W}$ solution $(14.1 \mathrm{GBq}$, $100 \mathrm{~mL}$ at $\mathrm{pH} \sim 3$ ) through the column at a flow rate of $1 \mathrm{~mL} / \mathrm{min}$. Rhenium-188 was regularly eluted from the ${ }^{188} \mathrm{~W} /{ }^{188} \mathrm{Re}$ generator in saline solution $[0.9 \% \mathrm{NaCl}(\mathrm{w} / \mathrm{v})$ solution prepared in deionized water] and the performance of the generator was evaluated over a period of 6 months. The details regarding preparation of the ${ }^{188} \mathrm{~W} /{ }^{188} \mathrm{Re}$ generator and its quality control are provided in the Supporting Information.

\section{Results and discussion}

\subsection{Synthesis and characterization of the sorbent}

The sorbent, mesoporous alumina, was synthesized by solid state mechanochemical reaction of aluminum isopropoxide with glucose, followed by calcination at $500^{\circ} \mathrm{C}$. The glucose acted as template which could be removed during calcination leading to formation of gases which resulted in creation of mesopores in the sorbent matrix $[8,9]$. The balanced chemical equation for this process can be written as:

$2 \mathrm{C}_{9} \mathrm{H}_{21} \mathrm{AlO}_{3}+\mathrm{C}_{6} \mathrm{H}_{12} \mathrm{O}_{6}+33 \mathrm{O}_{2} \rightarrow \mathrm{Al}_{2} \mathrm{O}_{3}+24 \mathrm{CO}_{2} \uparrow+27 \mathrm{H}_{2} \mathrm{O} \uparrow$

As predicted from this equation, 2 molecules of aluminum isopropoxide reacts with 1 molecule of glucose for getting 1 molecule of aluminum oxide product. However, in order to obtain higher mesoporosity and hence higher sorption capacity of mesoporous alumina, higher amount of glucose content (than the amount predicted from the balanced chemical equation) was required in the reaction mixture. For maximizing the sorption capacity, the molar ratios of the aluminum isopropoxide to glucose in the reaction mixture were varied and the reactions were carried out under identical conditions, as detailed in the Supporting Information. Based on the mesoporosity (Figure S1, Figure S2 and Table S1) and sorption capacity (Table S2) studies, the material synthesized by maintaining aluminum isopropoxide to glucose molar ratio in the reaction mixture as 1:1.5 was identified as the optimal material for preparation of the ${ }^{186} \mathrm{~W} /{ }^{188}$ Re generator. The material synthesized under the optimized synthetic condition was free flowing and exhibited adequate mechanical 
A

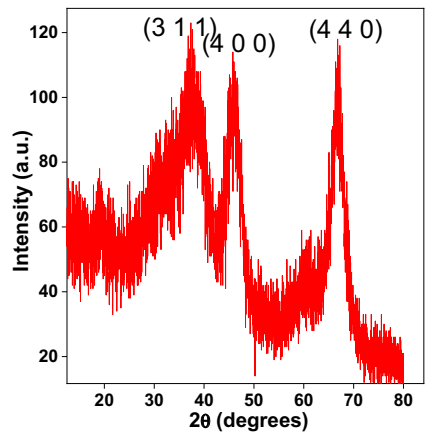

D

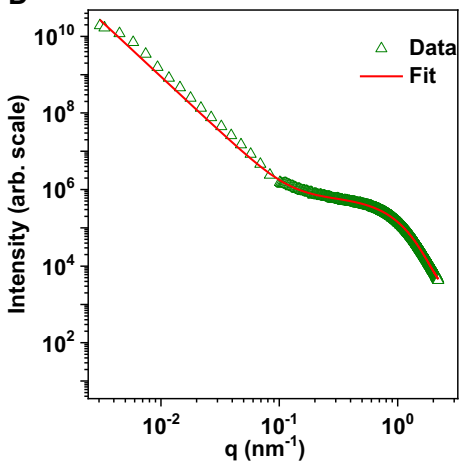

B

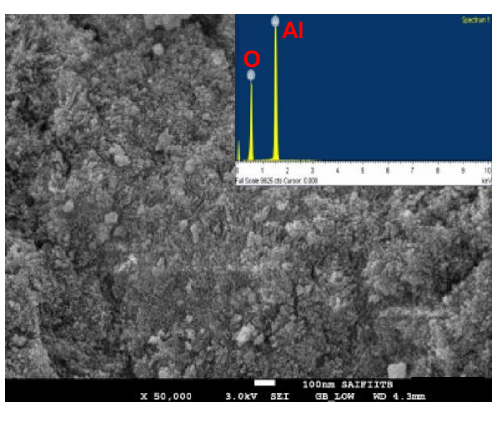

E

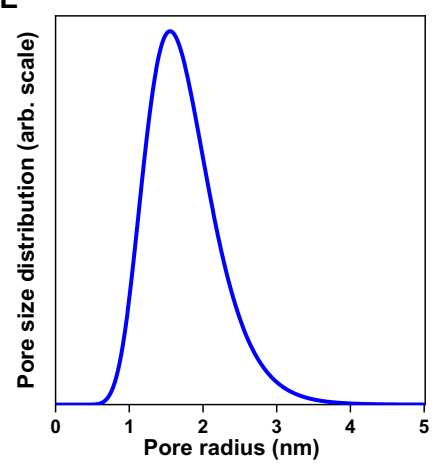

C

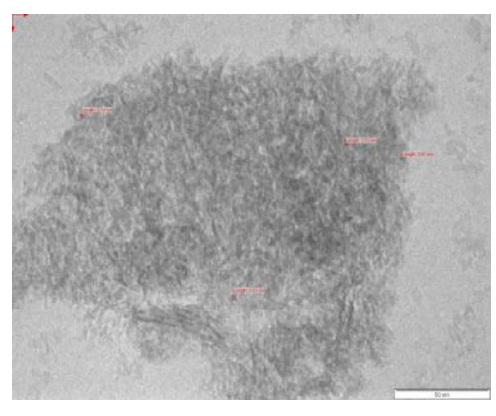

$\mathbf{F}$

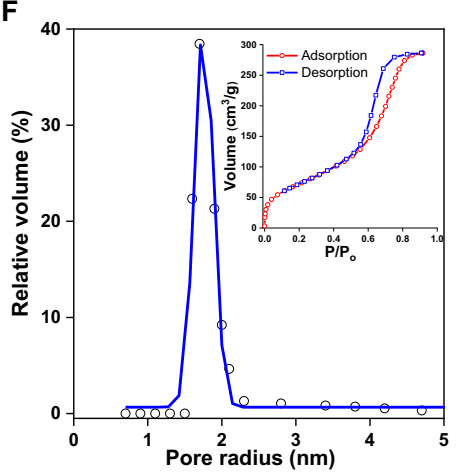

Fig. 1 Characterization of mesoporous alumina (a) XRD pattern, (b) SEM micrograph. Inset shows the EDS spectrum, (c) TEM micrograph, (d) Combined SAXS and MSANS profile. MSANS profiles are scaled to SAXS data in the overlapping q range, (e) Pore size distri- bution obtained from the SAXS-MSANS profile, (f) Pore size distribution from nitrogen adsorption desorption isotherm. Inset shows the type IV isotherm strength for use as a sorbent matrix in a chromatographic procedure.

The X-ray diffraction (XRD) pattern of mesoporous alumina indicated that the material is nanocrystalline, with peaks assigned to (3 11 1), (4 0 0) and (4 4 0) planes of cubic alumina (Fig. 1a). From the XRD pattern, the average crystallite size of the material was determined to be $2.4 \pm 0.1 \mathrm{~nm}$, using the standard Debye Scherrer's equation. The scanning electron microscopy (SEM) of the material showed worm-hole like structure which gives an idea that it is porous (Fig. 1b). The energy dispersive spectroscopy (EDS) showed peaks corresponding to $\mathrm{Al}$ and $\mathrm{O}$. The SEM image of the overall particles is shown in Figure $S 3 A$. The transmission electron microscopy (TEM) of the mesoporous alumina showed that the material is nanosized but highly agglomerated (Fig. 1c). Agglomeration is essential in order to use a nanomaterial as a sorbent matrix in a chromatographic column [20]. The crystallite size of the material as evident from the TEM micrograph was in the range of 2-4 $\mathrm{nm}$, which substantiated the results obtained from the XRD studies. The size distribution of the agglomerated particles as determined by laser diffraction technique is shown in Figure $S 3 B$ and the mean particle size was determined to be $57.3 \pm 1.6 \mu \mathrm{m}$.
The porous structure of the material was investigated by combined small angle X-ray scattering (SAXS) and medium resolution small-angle neutron scattering (MSANS) techniques, using a laboratory based SAXS and nuclear reactor based MSANS facility for accessing a wide $q$ range $[8,9]$. The scattering profile did not show any diffraction peak, indicating the absence of ordered pores in the material (Fig. 1d). From the SAXS-MSANS study, the pore size distribution showed that the average pore diameter of the material was $3.4 \pm 0.2 \mathrm{~nm}$, proving that it is mesoporous (Fig. 1e). This was further corroborated by conventional nitrogen adsorption-desorption method, which showed type IV isotherm characteristic of mesoporous materials and the average pore diameter was determined to be $3.6 \pm 0.3 \mathrm{~nm}$ (Fig. 1f).

The surface charge on mesoporous alumina was analyzed at different $\mathrm{pH}$ environments by determining the zeta potential (Table 1). Under the acidic conditions, the material showed positive zeta potential with maximum value $(48.5 \pm 3.7 \mathrm{mV})$ at $\mathrm{pH}$ 3. On increase of $\mathrm{pH}$ beyond 6 , the zeta potential became increasingly negative. The isoelectric point was attained between $\mathrm{pH} 6$ and 7. 
Table 1 Variation in zeta potential of mesoporous alumina and the $\mathrm{K}_{\mathrm{d}}$ values of tungstate and perrhenate ions at different $\mathrm{pH}$

\begin{tabular}{|c|c|c|c|}
\hline \multirow[t]{2}{*}{ Medium } & \multirow[t]{2}{*}{ Zeta potential $^{\mathrm{a}}(\mathrm{mV})$} & \multicolumn{2}{|l|}{$\mathrm{K}_{\mathrm{d}}^{\mathrm{a}}$} \\
\hline & & Tungstate & Perrhenate \\
\hline pH 1 & $23.2 \pm 1.8$ & $89,211 \pm 2313$ & $252 \pm 12$ \\
\hline $\mathrm{pH} 2$ & $47.6 \pm 4.2$ & $231,415 \pm 3141$ & $212 \pm 23$ \\
\hline $\mathrm{pH} 3$ & $48.5 \pm 3.7$ & $487,564 \pm 2199$ & $151 \pm 22$ \\
\hline $\mathrm{pH} 4$ & $40.7 \pm 2.9$ & $377,567 \pm 1877$ & $125 \pm 18$ \\
\hline $\mathrm{pH} 5$ & $31.7 \pm 1.9$ & $74,512 \pm 1223$ & $87 \pm 13$ \\
\hline $\mathrm{pH} 6$ & $22.7 \pm 2.6$ & $19,784 \pm 1458$ & $45 \pm 11$ \\
\hline $\mathrm{pH} 7$ & $-17.9 \pm 1.4$ & $11,754 \pm 1476$ & $13 \pm 6$ \\
\hline $\mathrm{pH} 8$ & $-19.5 \pm 1.8$ & $2436 \pm 177$ & $8.7 \pm 2.3$ \\
\hline $\mathrm{pH} 9$ & $-27.1 \pm 2.2$ & $811 \pm 78$ & $4.5 \pm 1.6$ \\
\hline pH 10 & $-33.9 \pm 2.8$ & $512 \pm 37$ & $3.2 \pm 0.7$ \\
\hline Saline & $7.6 \pm 1.5$ & $15,521 \pm 231$ & $0.2 \pm 0.1$ \\
\hline
\end{tabular}

${ }^{a}$ Average of three independent measurements with standard deviation is presented

\subsection{Sorption characteristics of mesoporous alumina}

In order to understand the sorption characteristics of mesoporous alumina, the distribution coefficients $\left(K_{d}\right)$ of tungstate and perrhenate ions were determined at different $\mathrm{pH}$ and the results are summarized in Table 1. Under all conditions, the $K_{d}$ values for tungstate ions are much higher than that of perrhenate ions, indicating the high affinity of the sorbent towards tungstate ions. The maximum $\mathrm{K}_{\mathrm{d}}$ value was obtained at $\mathrm{pH} 3$, indicating that this is the most favorable condition for sorption of ${ }^{188} \mathrm{~W}$ in the generator column. At $\mathrm{pH}<6$, tungstate ions polymerize to form highly negative polytungstate $\left[\mathrm{HW}_{6} \mathrm{O}_{21}\right]^{5-}$ ions [21]. It is pertinent to note that the zeta potential to the sorbent was maximum positive at $\mathrm{pH} 3$, resulting in high sorption of negatively charged $\left[\mathrm{HW}_{6} \mathrm{O}_{21}\right]^{5-}$ ions on mesoporous alumina. In saline solution, the $\mathrm{K}_{\mathrm{d}}$ value for tungstate ions is appreciably high $(15,521 \pm 231)$ and that for perrhenate ions is negligibly low $(0.2 \pm 0.1)$. Therefore, saline is a suitable medium for selective elution of ${ }^{188} \mathrm{Re}$ from the generator column.

The uptake of polytungstate ions on mesoporous alumina under acidic conditions is expected to occur in two steps. The first step is due to electrostatic attraction of negatively charged polytungstate ions on the positively charged surface of alumina under acidic conditions. In the second step, thermodynamically stable complexes of tetrahedrally coordinated aluminum atoms and $\mathrm{WO}_{4}{ }^{2-}$ tetrahedrons are formed, resulting in strong binding as evident from the high $\mathrm{K}_{d}$ values [22]. On the other hand, perrhenate ions cannot form complex with the alumina matrix and therefore manifests low $K_{d}$ values.
The tungstate sorption isotherm was analyzed at room temperature $(298 \mathrm{~K}$ ) by the following three models [23]:

Langmuir model:

$\mathrm{q}_{\mathrm{e}}=\frac{Q_{0} \cdot b C_{e}}{1+b C_{e}}$

A linear form of this equation is:

$\frac{C_{e}}{q_{e}}=\frac{1}{Q_{0} \cdot b}+\frac{C_{e}}{Q_{0}}$

where, $\mathrm{Q}_{0}$ and $\mathrm{b}$ are Langmuir constants that are related to the maximum sorption capacity and sorption energy, respectively.

Freundlich model

$\mathrm{q}_{\mathrm{e}}=\mathrm{K}_{\mathrm{F}} \mathrm{C}_{\mathrm{e}}^{1 / \mathrm{n}}$

Equation (4) can be rewritten as:

$\log \mathrm{q}_{\mathrm{e}}=\log \mathrm{K}_{\mathrm{F}}+\frac{1}{n} \log \mathrm{C}_{\mathrm{e}}$

where, $K_{F}$ is Freundlich constant and $n$ is Freundlich exponent (dimensionless).

Dubinin-Radushkevich (D-R) Isotherm

$\ln q_{e}=\ln X_{m}-\beta \varepsilon^{2}$

where, $X_{m}$ is the maximum sorption capacity, $\beta$ is the activity coefficient related to the mean sorption energy, and $\varepsilon$ is the Polanyi potential, which can be written as

$\varepsilon=\mathrm{RT} \ln \left(1+\frac{1}{C_{e}}\right)$

where, $\mathrm{R}$ is the universal gas constant [expressed in units of $\mathrm{kJ} /(\mathrm{mol} . \mathrm{K})$ ] and $\mathrm{T}$ is the temperature (in $\mathrm{K}$ ). In all these models, $\mathrm{q}_{\mathrm{e}}$ is the amount of tungstate ions adsorbed on mesoporous alumina at equilibrium (expressed in terms of $\mathrm{mg} / \mathrm{g}), C_{e}$ is the equilibrium concentration of metal ions (expressed in terms of $\mathrm{mg} / \mathrm{L}$ ). From the fittings (Fig. 2a, Figure S4), it could be inferred that the equilibrium data could be fitted well with Freundlich model with $R^{2}=0.99$, which implied that adsorption occurred on a heterogeneous surface, where the adsorption energy exponentially reduced with decrease in number of adsorption sites [24]. The values of $\mathrm{K}_{\mathrm{F}}$ and $1 / \mathrm{n}$ were determined to be $47.01 \mathrm{mg} \mathrm{g}^{-1}(\mathrm{mg}$ $\left.\mathrm{L}^{-1}\right)^{-1 / \mathrm{n}}$ and 0.24 , respectively. Because the value of $1 / \mathrm{n}$ is less than unity, it indicates a favorable adsorption [23].

The kinetics for tungstate sorption by mesoporous alumina was analyzed at room temperature ( $298 \mathrm{~K})$ by two kinetic models [23].

Pseudo-first-order reaction 
A
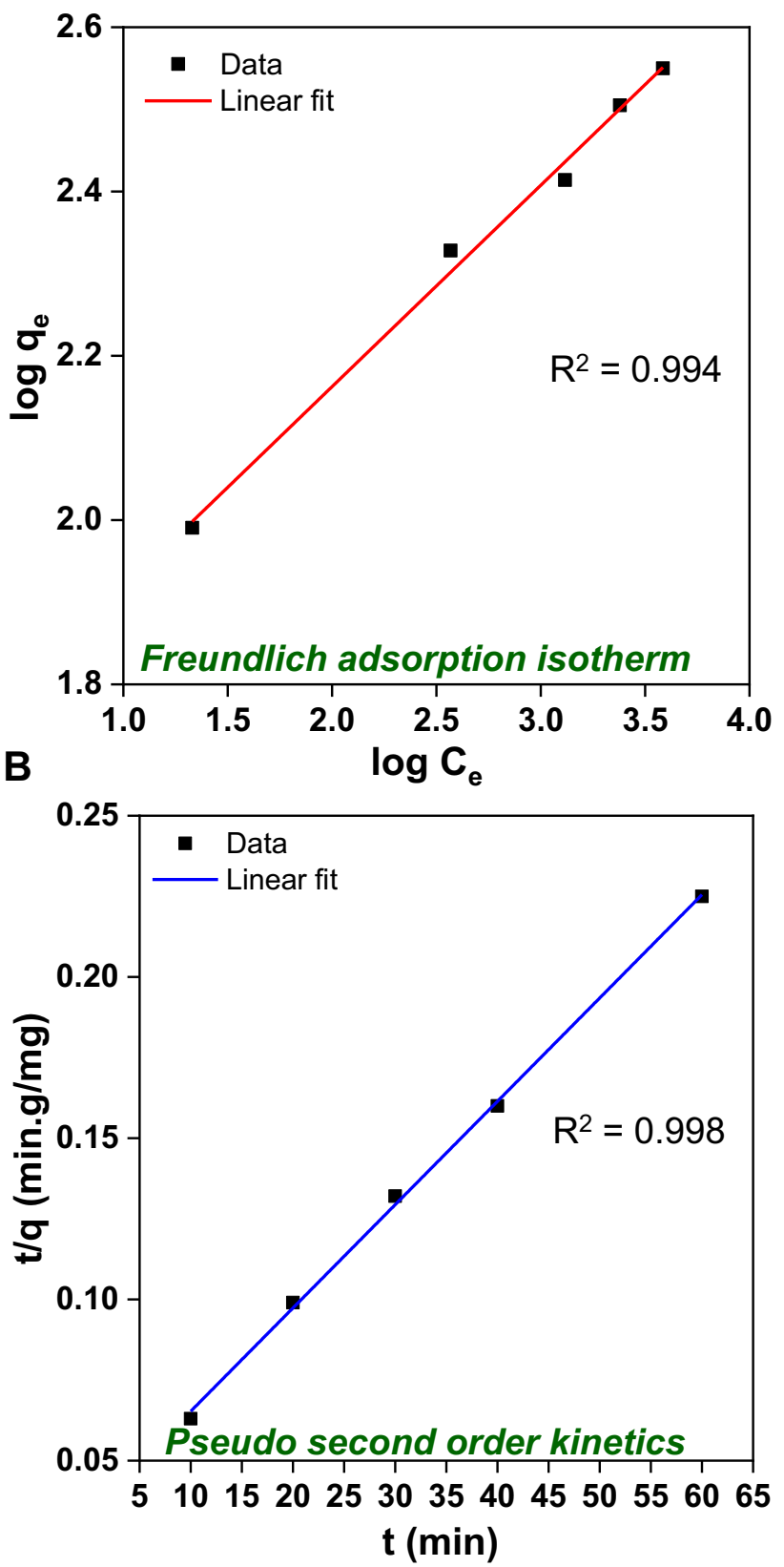

Fig. 2 Sorption of tungstate ions on mesoporous alumina. (a) Freundlich adsorption isotherm plot, (b) Pseudo second order kinetics plot

$\log \left(q_{e}-q\right)=\log q_{e}-\frac{k_{1} t}{2.303}$

Pseudo-second-order reaction

$\frac{d q}{d t}=\mathrm{k}_{2}\left(\mathrm{q}_{\mathrm{e}}-\mathrm{q}\right)^{2}$

where, $\mathrm{k}_{1}$ and $\mathrm{k}_{2}$ are the rate constants for the pseudo-firstorder and pseudo-second-order reactions respectively, $\mathrm{q}_{\mathrm{e}}$

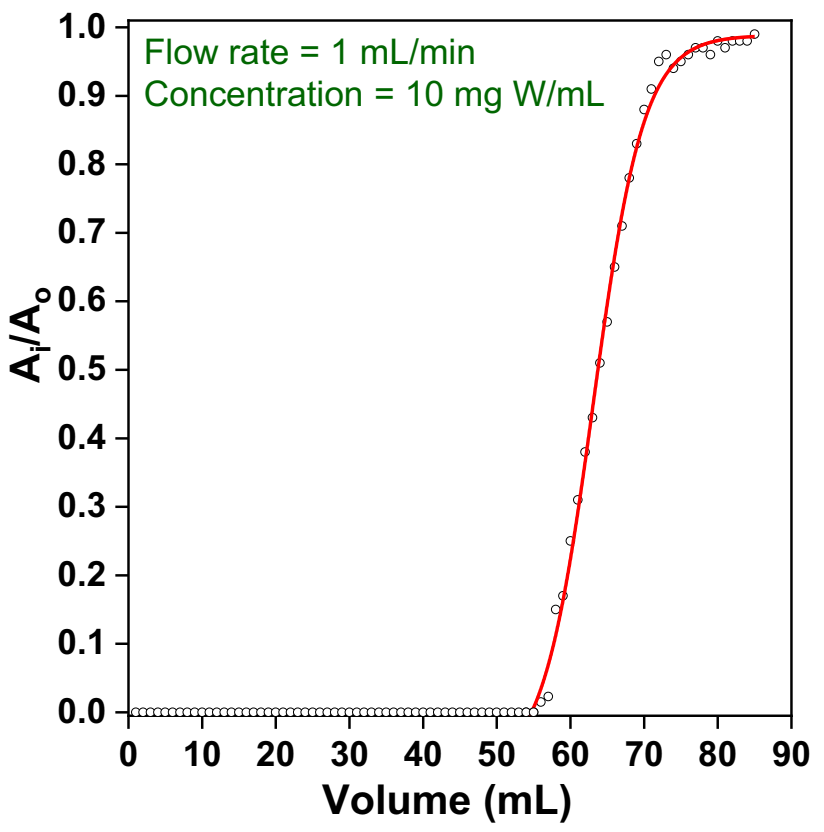

Fig. 3 Breakthrough profile on passing ${ }^{187} \mathrm{~W}$ solution (10 mg W/ $\mathrm{mL}, \mathrm{pH} \sim 3$ ) through a chromatographic column containing $1 \mathrm{~g}$ of mesoporous alumina

is the amount of metal ion adsorbed at equilibrium time (expressed in units of $\mathrm{mg} / \mathrm{g}$ ) and $\mathrm{q}$ is the amount of metal ion adsorbed at any time (also expressed in units of $\mathrm{mg} / \mathrm{g}$ ). Integrating Eq. (9) for the boundary conditions of $t=0$, $q=0$ gives the linear equation:

$t / q=1 /\left(k_{2} \times q_{e}^{2}\right)+\left(1 / q_{e}\right) t$

$h=k_{2} \times q_{e}^{2}$

From the fittings (Fig. 2b, Figure S5), it could be inferred that the sorption process follows pseudosecond-order kinetics indicating that the process is chemisorption and irreversible [25]. The kinetic parameters $\mathrm{k}_{2}, \mathrm{q}_{\mathrm{e}}$ and $\mathrm{h}$ were determined to be $3.07 \times$ $10^{-4} \mathrm{~g} \mathrm{~min}^{-1} \mathrm{mg}^{-1}, 312.5 \mathrm{mg} \mathrm{g}^{-1}$ and $30.1 \mathrm{mg} \mathrm{g}^{-1} \mathrm{~min}$, respectively. It is pertinent to mention here that adsorption mechanisms cannot be accurately assigned based on observing simple kinetic experiments or by fitting kinetic models [26, 27]. They can only be established by using several analytical techniques [27]. However, such studies have not been pursued as they were outside the scope of the present work.

Under dynamic conditions, the breakthrough capacity of the sorbent was determined to be $550 \pm 12 \mathrm{mg} \mathrm{W} / \mathrm{g}$ (Fig. 3), which is $\sim 10$ times higher than the conventionally used bulk alumina [28]. A comparative evaluation of the breakthrough capacity of mesoporous alumina 
Table 2 Comparison of the breakthrough capacity of mesoporous alumina with that of other sorbent materials reported in the literature

\begin{tabular}{lll}
\hline Sorbent & $\begin{array}{l}\text { Breakthrough } \\
\text { capacity } \\
\text { (mg/g) }\end{array}$ & References \\
\hline Polymeric zirconium compound & $\#$ & {$[14]$} \\
Polymeric titantium oxychloride & $\#$ & {$[16]$} \\
Synthetic alumina & 180 & {$[13]$} \\
Polymer embedded nanocrystalline & 102 & {$[18]$} \\
$\quad$ titania & 120 & {$[19]$} \\
Nanocrystalline zirconia & 300 & {$[15]$} \\
Nanocrystalline -alumina & 550 & This work \\
Mesoporous alumina &
\end{tabular}

\#Owing to the slow sorption kinetics, the sorption capacity under dynamic conditions was not determined

determined under dynamic conditions with that of other high capacity sorbents reported for the preparation of ${ }^{188} \mathrm{~W} /{ }^{188} \mathrm{Re}$ generator is provided in Table 2 . It can be seen from the table that the breakthrough capacity of mesoporous alumina is much higher than that of other reported materials, which demonstrates its suitability for preparation of clinical-scale ${ }^{188} \mathrm{~W} /{ }^{188}$ Re generator.

\subsection{Production of ${ }^{188} \mathrm{~W}$ and development of ${ }^{188} \mathrm{~W} /{ }^{188}$ Re generator}

The theoretical specific activity of ${ }^{188} \mathrm{~W}$ calculated using simplified Bateman equation under different neutron flux conditions is shown in Figure S6. The specific activity of ${ }^{188} \mathrm{~W}$ increased with increase in flux and an irradiation period of $\sim 6$ months was required to get appreciable specific activity. On irradiation of $1.25 \mathrm{~g}$ of enriched $(99.9 \%$ in ${ }^{186} \mathrm{~W}$ ) tungsten oxide target at a flux of $1.5 \times 10^{14} \mathrm{n} \cdot \mathrm{cm}^{-2}$. $\mathrm{s}^{-1}$ for 6 months, $15.1 \pm 0.4 \mathrm{GBq}$ of ${ }^{188} \mathrm{~W}$ could be produced with a specific activity of $15.0 \pm 0.3 \mathrm{GBq} / \mathrm{g}$ which is comparable to that obtained by theoretical calculation.

A $14.0 \mathrm{GBq}{ }^{188} \mathrm{~W} /{ }^{188}$ Re generator (Figure S7) was developed and its performance was evaluated over a period of 6 months. The elution profile of the generator was recorded at the beginning of every month and shown in Fig. 4a. The elution profiles are reasonably sharp and they gradually broadened with passage of time. The gradual broadening in elution profiles is not unexpected and is due to decay loss of ${ }^{188} \mathrm{~W}$ and repeated elution of ${ }^{188} \mathrm{Re}$ from the same generator column over a prolonged period of time. Nevertheless, it can be seen from the elution profiles that ${ }^{188}$ Re could be quantitatively eluted in $8 \mathrm{~mL}$ of saline solution. In the conventional bulk alumina based ${ }^{188} \mathrm{~W} /{ }^{188}$ Re generators, a much larger volume of saline solution (>15-20 mL) is required for elution of ${ }^{188} \operatorname{Re}$ [29].
As evident from the elution profiles (Fig. 4a), the radioactive concentration of ${ }^{188} \mathrm{Re}$ could be further increased by adopting fractionated elution approach. The elution yield of ${ }^{188}$ Re was initially $90 \%$ and it marginally decreased over the period of 6 months of study (Fig. 4b). A typical $\mathrm{Y}$-spectrum of ${ }^{188} \mathrm{Re}$ eluted from the generator is shown in Figure S8. From the analyses of the decayed samples of ${ }^{188} \mathrm{Re}$, the level of ${ }^{188} \mathrm{~W}$ impurity could be quantified as $<10^{-4} \%$ over the 6 months of elution (Fig. 4c). The radiochemical purity of ${ }^{188} \mathrm{Re}$ in the form of $\mathrm{ReO}_{4}{ }^{-}$was $>98 \%$, as determined by the paper chromatographic study (Figure 59). Inductively coupled plasma-atomic emission spectroscopy (ICP-AES) analysis of the decayed samples revealed that the level of tungsten impurity was below detectable limit $(<0.01 \mathrm{ppm})$ and the level of $\mathrm{Al}$ ions was $0.11 \pm 0.02 \mathrm{ppm}$. No other trace metal impurity could be detected in the ${ }^{188}$ Re samples indicating high chemical purity for preparation of radiopharmaceuticals. This performance remained consistent even after 6 months of usage of the ${ }^{188} \mathrm{~W} /{ }^{188} \mathrm{Re}$ generator, indicating high stability of the mesoporous alumina sorbent even in intense radiation environment. If mesoporous alumina sorbent did not retain its stability over a prolonged period of time, deteriorating performance of the ${ }^{188} \mathrm{~W} /{ }^{188} \mathrm{Re}$ generator in terms of increased ${ }^{188} \mathrm{~W}$ breakthrough and significant amounts of $\mathrm{Al}$ ions impurity would have been observed in the ${ }^{188} \mathrm{Re}$ eluate.

In all the batches, the ${ }^{188}$ Re eluate was found to be sterile and the level of bacterial endotoxins was $<25 \mathrm{EU}$, which is within acceptable limit as per Indian Pharmacopeia [30]. Overall, it could be inferred from these quality control studies that ${ }^{188} \mathrm{Re}$ obtained from this generator was amenable for use in clinical context.

\section{Conclusions}

In summary, solid state mechanochemistry has been found to be a viable method for synthesis of mesoporous alumina sorbent for preparation of chromatographic ${ }^{188} \mathrm{~W} /{ }^{188} \mathrm{Re}$ generator using ${ }^{188} \mathrm{~W}$ produced in a medium flux research reactor. The sorbent exhibits high sorption capacity $(\sim 550 \mathrm{mg} \mathrm{W} / \mathrm{g})$, which is adequate for preparation of clinical-scale generator. The ${ }^{188} \mathrm{Re}$ obtained from this chromatographic generator met all the requirements for clinical use. Adoption of this strategy would aid towards wider availability of ${ }^{188} \mathrm{~W} /{ }^{188}$ Re generators for clinical use at more affordable cost, since ${ }^{188} \mathrm{~W}$ produced in medium flux research reactors could be effectively utilized. This would be especially beneficial for developing countries which do not have access to high flux research reactors for radioisotope production. 
A

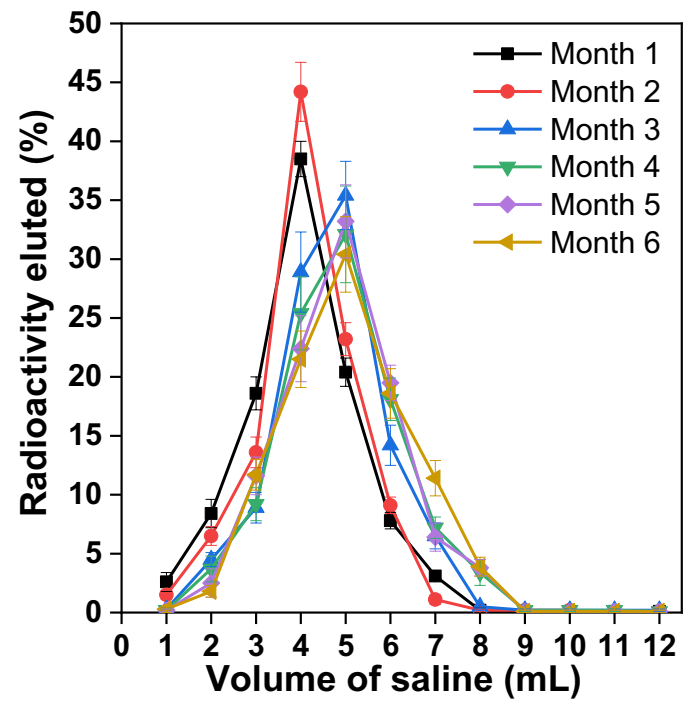

B

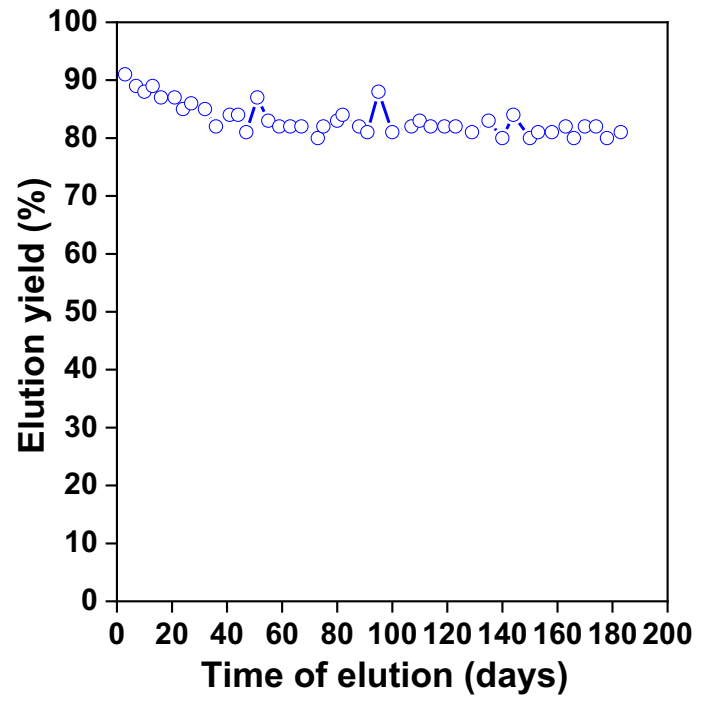

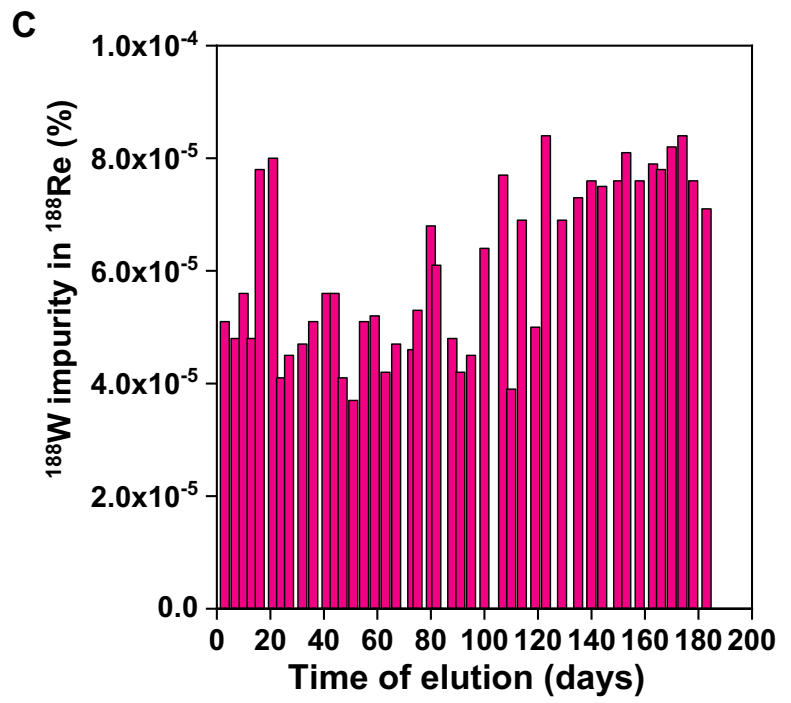

Fig. 4 Performance evaluation of the ${ }^{188} \mathrm{~W} /{ }^{188}$ Re generator over a period of 6 months (a) Elution profiles at the beginning of each month, (b) Elution yield, (c) Level of ${ }^{188} \mathrm{~W}$ impurity in ${ }^{188} \mathrm{Re}$

Acknowledgements The authors are grateful to Dr. P. K. Pujari, Director, Radiochemistry and Isotope Group, Bhabha Atomic Research Centre (BARC) for his valuable support to the Isotope Program. The Irradiation Coordination Group of Radiopharmaceuticals Division, BARC is gratefully acknowledged for facilitating irradiation of targets in the Dhruva reactors. Thanks are due to Analytical Chemistry Division, BARC for ICP-AES analysis of the samples.

\section{Compliance with ethical standards}

Conflict of interest The authors declare no conflict of interest.
Open Access This article is licensed under a Creative Commons Attribution 4.0 International License, which permits use, sharing, adaptation, distribution and reproduction in any medium or format, as long as you give appropriate credit to the original author(s) and the source, provide a link to the Creative Commons licence, and indicate if changes were made. The images or other third party material in this article are included in the article's Creative Commons licence, unless indicated otherwise in a credit line to the material. If material is not included in the article's Creative Commons licence and your intended use is not permitted by statutory regulation or exceeds the permitted use, you will need to obtain permission directly from the copyright holder. To view a copy of this licence, visit http://creativecommons .org/licenses/by/4.0/. 


\section{References}

1. Dash A, Chakravarty R (2014) Pivotal role of separation chemistry in the development of radionuclide generators to meet clinical demands. RSC Adv 4:42779-42803. https://doi.org/10.1039/ C4RA07218A

2. Dash A, Chakravarty R (2017) Nanomaterial-based adsorbent: promises, opportunities, and challenges to develop column chromatography radionuclide generators for nuclear medicine. Sep Purif Rev 46:91-107. https://doi.org/10.1080/15422 119.2016.1205089

3. Yamauchi Y, Nagaura T, Ishikawa A, Chikyow T, Inoue S (2008) Evolution of standing mesochannels on porous anodic alumina substrates with designed conical holes. J Am Chem Soc 130:10165-10170. https://doi.org/10.1021/ja7107036

4. Wu C-W, Yamauchi Y, Ohsuna T, Kuroda K (2006) Structural study of highly ordered mesoporous silica thin films and replicated Pt nanowires by high-resolution scanning electron microscopy (HRSEM). J Mater Chem 16:3091-3098. https://doi.org/10.1039/ B604062D

5. Nandi M, Mondal J, Sarkar K, Yamauchi Y, Bhaumik A (2011) Highly ordered acid functionalized SBA-15: a novel organocatalyst for the preparation of xanthenes. Chem Commun 47:66776679. https://doi.org/10.1039/C1CC11007A

6. Malgras V, Henzie J, Takei T, Yamauchi Y (2018) Stable blue luminescent $\mathrm{CsPbBr}_{3}$ perovskite nanocrystals confined in mesoporous thin films. Angew Chem Int Ed Engl 57:8881-8885. https://doi.org/10.1002/anie.201802335

7. Jiang B, Guo Y, Kim J, Whitten AE, Wood K, Kani K, Rowan AE, Henzie J, Yamauchi Y (2018) Mesoporous metallic iridium nanosheets. J Am Chem Soc 140:12434-12441. https://doi. org/10.1021/jacs.8b05206

8. Chakravarty R, Chakraborty S, Shukla R, Bahadur J, Ram R, Mazumder S, Dev Sarma H, Tyagi AK, Dash A (2016) Mechanochemical synthesis of mesoporous tin oxide: a new generation nanosorbent for ${ }^{68} \mathrm{Ge} /{ }^{68} \mathrm{Ga}$ generator technology. Dalton Trans 45:13361-13372. https://doi.org/10.1039/C6DT01921H

9. Chakravarty R, Bahadur J, Lohar S, Sarma HD, Sen D, Mishra R, Chakraborty S, Dash A (2019) Solid state synthesis of mesoporous alumina: a viable strategy for preparation of an advanced nanosorbent for ${ }^{99} \mathrm{Mo} /{ }^{99 \mathrm{~m}} \mathrm{Tc}$ generator technology. Micropor Mesopor Mat 287:271-279. https://doi.org/10.1016/j. micromeso.2019.06.020

10. Dash A, Knapp FF Jr (2015) An overview of radioisotope separation technologies for development of ${ }^{188} \mathrm{~W} /{ }^{188}$ Re radionuclide generators providing ${ }^{188}$ Re to meet future research and clinical demands. RSC Adv 5:39012-39036. https://doi.org/10.1039/ C5RA03890A

11. IAEA Research Reactor Database. Accessible online at: https:// nucleus.iaea.org/RRDB/RR/ReactorSearch.aspx

12. Boschi A, Uccelli L, Pasquali M, Duatti A, Taibi A, Pupillo G, Esposito J (2014) ${ }^{188} \mathrm{~W} /{ }^{188}$ Re generator system and its therapeutic applications. J Chem 2014:529406. https://doi. org/10.1155/2014/529406

13. Lee JS, Lee JS, Park UJ, Son KJ, Han HS (2009) Development of a high performance ${ }^{188} \mathrm{~W} /{ }^{188}$ Re generator by using a synthetic alumina. Appl Radiat Isot 67:1162-1166. https://doi.org/10.1016/j. apradiso.2009.02.062

14. Matsuoka $\mathrm{H}$, Hasimoto $\mathrm{K}$, Hishinuma $\mathrm{Y}$, Ishikawa $\mathrm{K}$, Terenuma $\mathrm{H}$, Tatenuma K, Uchida S (2005) Application of PZC to ${ }^{188} \mathrm{~W} /{ }^{188} \mathrm{Re}$ generators. J Nucl Radiochem Sci 6:189-191

15. Chakravarty $R$, Shukla R, Ram R, Venkatesh M, Tyagi AK, Dash A (2011) Exploitation of nano alumina for the chromatographic separation of clinical grade ${ }^{188} \mathrm{Re}$ from ${ }^{188} \mathrm{~W}$ : a renaissance of the ${ }^{188} \mathrm{~W} /{ }^{188}$ Re generator technology. Anal Chem 83:6342-6348. https://doi.org/10.1021/ac201232m

16. So LV, Nguyen CD, Pellegrini P, Bui VC (2009) Polymeric titanium oxychloride sorbent for ${ }^{188} \mathrm{~W} /{ }^{188}$ Re nuclide pair separation. Sep Sci Technol 44:1074-1098. https://doi.org/10.1080/0149639090 2728819

17. Chakravarty R, Dash A (2013) Nano structured metal oxides as potential sorbents for ${ }^{188} \mathrm{~W} /{ }^{188} \mathrm{Re}$ generator: a comparative study. Sep Sci Technol 48:607-616. https://doi. org/10.1080/01496395.2012.713433

18. Chakravarty R, Dash A, Venkatesh M (2009) Separation of clinical grade ${ }^{188} \mathrm{Re}$ from ${ }^{188} \mathrm{~W}$ using polymer embedded nanocrystalline titania. Chromatographia 69:1363-1372. https://doi. org/10.1365/s10337-009-1070-7

19. Chakravarty R, Shukla R, Tyagi AK, Dash A, Venkatesh M (2010) Nanocrystalline zirconia: a novel sorbent for the preparation of ${ }^{188} \mathrm{~W} /{ }^{188}$ Re generator. Appl Radiat Isot 68:229-238. https://doi. org/10.1016/j.apradiso.2009.10.031

20. Chakravarty R, Dash A (2013) Role of nanoporous materials in radiochemical separations for biomedical applications. J Nanosci Nanotechnol 13:2431-2450. https://doi.org/10.1166/ jnn.2013.7349

21. Khalid M, Mushtaq A, Iqbal MZ (2001) Sorption of tungsten (VI) and rhenium (VII) on various ion-exchange materials. Sep Sci Technol 36:283-294. https://doi.org/10.1081/SS-100001079

22. Dadachova E, Mirzadeh S, Lambrecht RM (1995) Tungstate-ionalumina interaction in a ${ }^{188} \mathrm{~W} /{ }^{188}$ Re biomedical generator. J Phys Chem 99:10976-10981. https://doi.org/10.1021/j100027a044

23. Saxena S, Prasad M, D'Souza SF (2006) Radionuclide sorption onto low-cost mineral adsorbent. Ind Eng Chem Res 45:91229128. https://doi.org/10.1021/ie060378r

24. Xiao X, Hayashi F, Shiiba H, Selcuk S, Ishihara K, Namiki K, Shao L, Nishikiori H, Selloni A, Teshima K (2016) Platy $\mathrm{KTiNbO}_{5}$ as a selective $\mathrm{Sr}$ ion adsorbent: crystal growth, adsorption experiments, and DFT calculations. J Phys Chem C 120:11984-11992. https:// doi.org/10.1021/acs.jpcc.6b02422

25. Rathore E, Pal P, Biswas K (2017) Layered metal chalcophosphate (K-MPS-1) for efficient, selective, and ppb level sequestration of $\mathrm{Pb}$ from water. J Phys Chem C 121:7959-7966. https://doi. org/10.1021/acs.jpcc.7b00908

26. Kumar KV (2006) Comments on "Adsorption of acid dye onto organobentonite." J Hazard Mater 137:638-639. https://doi. org/10.1016/j.jhazmat.2006.03.056

27. Lima ÉC, Adebayo MA, Machado FM (2015) Kinetic and equilibrium models of adsorption. In: Bergmann CP, Machado FM (eds) Carbon nanomaterials as adsorbents for environmental and biological applications. Springer, Cham, pp 33-69

28. Jeong JM, Knapp FF Jr (2008) Use of the Oak Ridge National Laboratory tungsten-188/rhenium-188 generator for preparation of the rhenium-188 HDD/lipiodol complex for trans-arterial liver cancer therapy. Semin Nucl Med 38:S19-29. https://doi. org/10.1053/j.semnuclmed.2007.10.003

29. Guhlke S, Beets AL, Oetjen K, Mirzadeh S, Biersack HJ, Knapp FF Jr (2000) Simple new method for effective concentration of ${ }^{188}$ Re solutions from alumina-based ${ }^{188} \mathrm{~W}-{ }^{188}$ Re generator. J Nucl Med 41:1271-1278

30. Indian Pharmacopoeia (2014) Test for Sterility (2.2.11), Test for Bacterial Endotoxin (2.2.3), Radiopharmaceutical Preparation, $p$ 3393

Publisher's Note Springer Nature remains neutral with regard to jurisdictional claims in published maps and institutional affiliations. 